It is comprehensive, taking the reader through the process of becoming a doctor from trying to analyse why we choose medicine (unsuccessfully) through to an outline of training and examinations for the postgraduate specialties.

I did, however, find the writing style rather heavy, bordering on the pedantic. The accounts of student life were stodgy and read more like the offerings for a GCSE essay than a vibrant account of life as a medic - even with its downside. While reference was made to the widespread changes in undergraduate learning throughout the country, the author could have expanded on this as, arguably, along with choosing a conducive environment, the way in which students 'learn medicine' is the most important decision to make - whether the traditional large lecture or the smaller problem-based tutorial system. I had other more trivial objections - my Scottish surgical colleagues would not like being referred to as 'Doctor', - they are definitely 'Mister' - (or in rarer cases 'Miss') whereas it is the Scottish gynaecologists who maintain their hardwon title; I did not recognise the ward-round with the retinue of juniors as described by Prof Richards - such things I thought had long disappeared with the reduction in junior doctor's hours - but maybe things are different in London!

Having said that, the book contains much useful information and is well worth reading by all prospective medical students, their parents and their teachers.

A GARDEN

Department of Obstetrics E Gynaecology, The University of Liverpool, Liverpool L69 3BX, UK

\section{The internet}

Medical information on the internet. A guide for health professionals, R Kiley. pp $x+133$, illustrated. Churchill Livingstone, London, 1996. $£ 16.95$, paperback

I rarely read every word when asked to review a book as some of them can be very long and tedious. In this case, however, being a relative newcomer to the internet, I decided I should read the entire book, and surprisingly I greatly enjoyed it. There are many useful features to tell you how to go about getting started in the internet, and I found it well put together and certainly for a relative novice a most useful introduction. Previously I have had to rely heavily on my sons at university who are much more computer-literate than I am, but I now feel that, at least as far as surfing the internet is concerned, or crawling the web, that I am able to compete. I would therefore recommend this book.

A MORRIS

Royal Liverpool University Hospital, Liverpool L7 8XP, UK

\section{Evidence-based medicine}

How to practice \& teach EBM, DL Sackett, et al. pp xii+250. illustrated. Churchill Livingstone, London, 1997. $£ 14.99$, paperback

The back cover of this handy little book poses four questions. Do you want to integrate the best available evidence with your clinical expertise? Do you worry that sometimes you don't? Do you want to get better at turning clinical problems into answerable questions? Do you want to enhance your ability to apply and teach evidence-based medicine in your everyday practice - in the clinic and the bedside?

If you answered yes to any of these then you will probably find this book useful. It is well referenced and the reader is guided through the text by a series of marginal icons. There is an excellent section on formulating answerable questions. The second section deals with searching for the best evidence. For some this will be the most useful section of the book, since it introduces a number of sources which have become important over the last few years. The authors give a great deal of help on how to use the internet and how to construct a useful Medline search. Subsequent sections cover appraising the evidence, deciding whether to apply it and evaluating the outcomes.

Medical students will find the book useful, especially the sections on formulating questions and searching for and appraising evidence. Junior doctors will find the sections on application and evaluation useful, and probably make most use of the five helpful prompt cards. More established clinicians and teachers will find this book both stimulating and useful. The authors have a web-page at URL http://cebm.jr2.ox.ac.uk

CM TAYLOR Faculty of Medicine Physiological Laboratory Liverpool L69 3BX, UK 